\title{
Supporting Informations for: Streptavidin homologs for applications on solid surfaces at high temperatures
}

\author{
Carsten Schmidt ${ }^{1}$, Peter Schierack ${ }^{1}$, Ulrike Gerber ${ }^{1}$, Christian Schröder $^{1}$, Youngeun \\ Choi $^{2,3}$, Ilko Bald ${ }^{2,3}$, Werner Lehmann ${ }^{4}$, Stefan Rödiger ${ }^{1,5^{*}}$ \\ *corresponding author: Email:stefan.roediger@b-tu.de, Phone: ++49 357385936 \\ ${ }^{1}$ Brandenburg University of Technology Cottbus - Senftenberg, Faculty of Environment and Natural Sciences, \\ Institute of Biotechnology, Universitätsplatz 1, D-01968 Senftenberg, Germany \\ 2University of Potsdam, Optical Spectroscopy and Chemical Imaging, Institute of Chemistry, Karl-Liebknecht- \\ Straße 24-25, Building 29, D-14476 Potsdam
}

${ }^{3}$ BAM Federal Institute for Materials Research and Testing, Division 1 - Analytical Chemistry and Reference Materials, Richard-Willstätter Str. 11, 12489 Berlin

${ }^{4}$ Attomol GmbH, Schulweg 6, D-03205 Bronkow (Lipten), Germany

${ }^{5}$ Faculty of Health Sciences, joint Faculty of the Brandenburg University of Technology Cottbus - Senftenberg, the Brandenburg Medical School Theodor Fontane and the University of Potsdam, Universitätsplatz 1, D-01968 Senftenberg, Germany

Number of pages: 5

Number of figures: 1

Number of tables: 1

This document contains additional information for the experimental section. First of all, a detailed description of the recombinant expression and purification of some streptavidin horologes is given (S-1). Moreover, in addition to figure 2 of the manuscript showing the principle of VideoScan measurements we give a more detailed picture of the VideoScan device with the heating and cooling unit (HCU). 


\section{S-1 Generation of streptavidin, traptavidin, core traptavidin and monomeric streptavidin intransformed E.coli}

Some streptavidin homologs (SAH) were recombinantly generated in E. coli transformed with expression plasmids shown in Table S1-1. For SAH expression 4

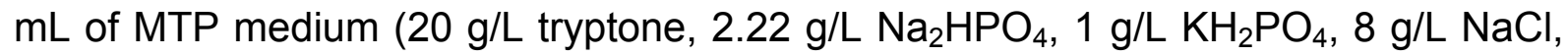
$15 \mathrm{~g} / \mathrm{L}$ Yeast Extract, $\mathrm{pH}$ 7.4) containing $200 \mu \mathrm{g} / \mathrm{mL}$ ampicillin and $50 \mu \mathrm{g} / \mathrm{mL}$ chloramphenicol was inoculated with transformed E. coli and incubated overnight at $37^{\circ} \mathrm{C}$. Suspensions were diluted with $10 \mathrm{ml}$ of prewarmed $20 \%$ glucose solution and then poured into $250 \mathrm{ml}$ MTP medium containing $200 \mu \mathrm{g} / \mathrm{mL}$ ampicillin but no chloramphenicol. Once the OD reached 0.8-1.0, expression was induced by adding $500 \mu \mathrm{M}$ IPTG. After $3 \mathrm{~h}$, cells were spun down and the supernatant was discarded. The pellet was resuspended in 15-20 ml binding buffer $\mathrm{BP}\left(50 \mathrm{mM} \mathrm{Na}_{2} \mathrm{CO}_{3}, 500 \mathrm{mM}\right.$ $\mathrm{NaCl}, \mathrm{pH} 11)$ and cells were lysed by French pressing two times. Before removing the cell debris by centrifugation at $5000 \mathrm{rpm}$ for $20 \mathrm{~min}$, the suspension was incubated at $75^{\circ} \mathrm{C}$ for $10 \mathrm{~min}$.

In the case of SA, TA and CA supernatants were mixed with $1 \mathrm{~mL} 2$-iminobiotinagarose resin (Sigma, St. Louis, MO, USA) for $1 \mathrm{~h}$ at $4^{\circ} \mathrm{C}$. The resin was washed two times with $15 \mathrm{ml}$ of BP buffer, before transfer into a column, where the washing was continued until the OD at $280 \mathrm{~nm}$ reached a constant level. Then the resin was eluted in several $500 \mu \mathrm{L}$ fractions of $1 \%$ acetic acid. Protein containing fractions were combined and the acetic acid was exchanged by diluted PBS buffer $(2.5 \mathrm{mM} \mathrm{Na}-$ phoshate $\mathrm{pH} 7.4,7.5 \mathrm{mM} \mathrm{NaCl}$ ) using Amicon Ultra centrifugal filters with a $30 \mathrm{kDa}$ cutoff. Final protein concentrations were about $2 \mathrm{mg} / \mathrm{mL}$.

In the case of mSA, purification was done according to Lim et al. ${ }^{9}$ by use of Ni-NTAaffinity chromatography (HisPur ${ }^{\mathrm{TM}}$-Ni-NTA-resin, Thermo Scientific) and missed only the final gel filtration step. $\mathrm{mSA}$ was dissolved in diluted PBS buffer $(\sim 2 \mathrm{mg} / \mathrm{mL})$ like for the other proteins. 


\begin{tabular}{|l|l|l|}
\hline $\begin{array}{l}\text { The quality of SA } \\
\text { and SAHs was } \\
\text { verified by SDS- } \\
\text { PAGE. Samples }\end{array}$ & plasmid & E.coli strain \\
\hline SA & pET11a-SA & BL21DE3-pLys \\
\hline TA & pET21a-TA & BL21DE3-RIPL \\
\hline CT & pET21a-CTa & BL21DE3-RIPL \\
\hline mSA & $\begin{array}{l}\text { pRSET- } \\
m s \Delta b\end{array}$ & BL21DE3-RIPL \\
\hline
\end{tabular}

Table S1-1: Expression plasmids and E.coli strains for generation of SAHs.

a pET21a-Traptavidin (Addgene plasmid \# 24753) and pET21a-Core traptavidin (Addgene plasmid \# 26054) were gifts from Mark Howard.

b pRSET-mSA (Addgene plasmid \# 39860) was a gift from Sheldon Park. 


\section{Detailed picture of the VideoScan-measurement devices}

The VideoScan system is a highly versatile imaging platform for analysis of cellular and biomolecular interaction. The technology can be used to measure assays in solution, on microbeads, on cells or a combination thereof. Applications include for example assays for human diagnostics ${ }^{1-5}$ and medical microbiology $y^{6,7}$. The hardware for the heating and cooling unit is shown in figure $\mathrm{S} 1-1$.
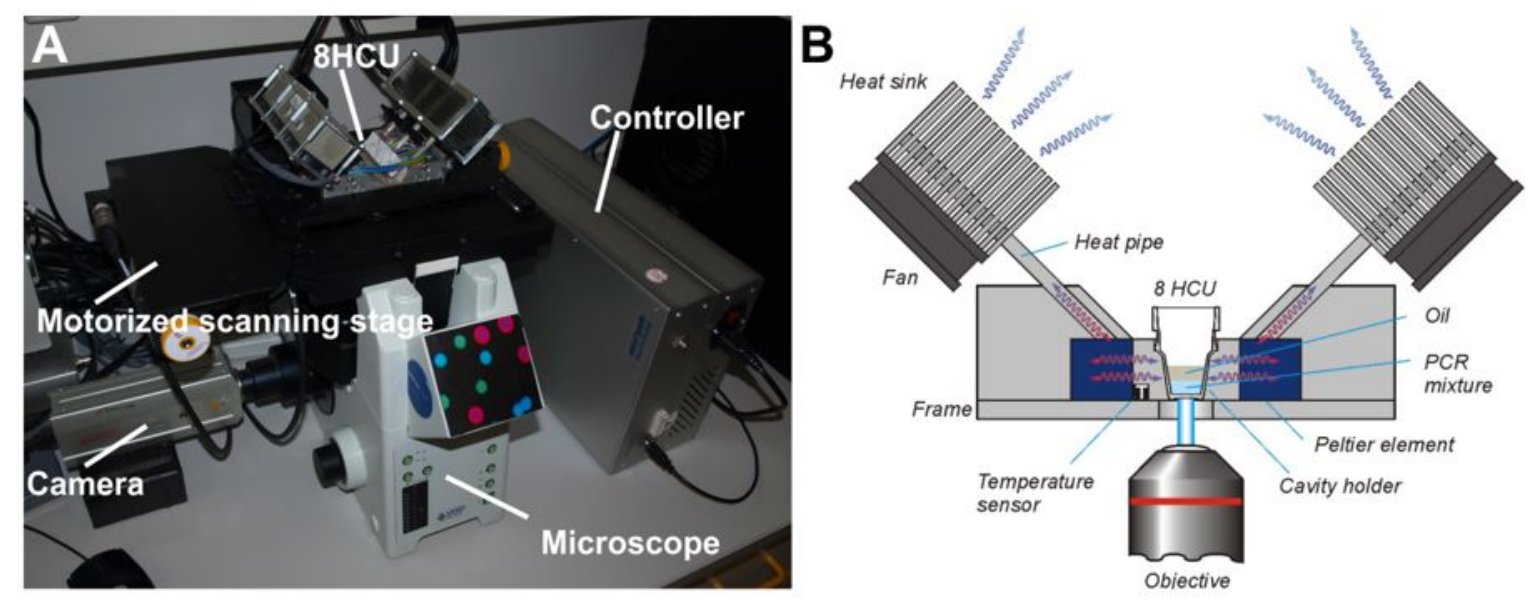

Figure S1-1: (A) show the main components of VideoScan: A motorized stage is mounted on a fluorescence microscope. The stage is equipped with the heating and cooloing unit

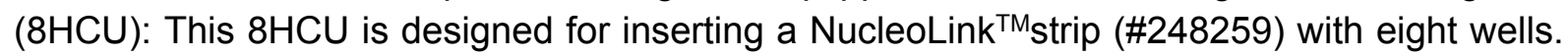
The device is an extension of the previously published $1 \mathrm{HCU}^{1}$. Each of its eight cavities can be exposed to a individual temperature profile, so that eight different PCR-reactions can be run in parallel. Figure (B) shows the components of the $8 \mathrm{HCU}$. The cavities of a NucleoLink ${ }^{\mathrm{TM}}$ strip have transparent bottoms, so that microbeads on that bottom can be observed with a microscope objective. To generate the temperature profiles not only peltier elements are necessary, but also effective heat sinks. The device can be used for the realtime measurements including quantitative PCRs ${ }^{1}$ and surface melting curve analyses ${ }^{8}$. 


\section{References}

(1) Rödiger, S.; Schierack, P.; Böhm, A.; Nitschke, J.; Berger, I.; Frömmel, U.; Schmidt, C.; Ruhland, M.; Schimke, I.; Roggenbuck, D.; et al. A Highly Versatile Microscope Imaging Technology Platform for the Multiplex Real-Time Detection of Biomolecules and Autoimmune Antibodies. Adv. Biochem. Eng. Biotechnol. 2013, 133, 35-74. https://doi.org/10.1007/10_2011_132.

(2) Rödiger, S.; Liebsch, C.; Schmidt, C.; Lehmann, W.; Resch-Genger, U.; Schedler, U.; Schierack, P. Nucleic Acid Detection Based on the Use of Microbeads: A Review. Microchim Acta 2014, 181 (11-12), 1151-1168. https://doi.org/10.1007/s00604-0141243-4.

(3) Grossmann, K.; Roggenbuck, D.; Schröder, C.; Conrad, K.; Schierack, P.; Sack, U. Multiplex Assessment of Non-Organ-Specific Autoantibodies with a Novel MicrobeadBased Immunoassay. Cytometry A 2011, 79 (2), 118-125. https://doi.org/10.1002/cyto.a.21009.

(4) Scholz, J.; Grossmann, K.; Knütter, I.; Hiemann, R.; Sowa, M.; Röber, N.; Rödiger, S.; Schierack, P.; Reinhold, D.; Bogdanos, D. P.; et al. Second Generation Analysis of Antinuclear Antibody (ANA) by Combination of Screening and Confirmatory Testing. Clin. Chem. Lab. Med. 2015, 53 (12), 1991-2002. https://doi.org/10.1515/cclm-20150083.

(5) Rödiger, S.; Ruhland, M.; Schmidt, C.; Schröder, C.; Grossmann, K.; Böhm, A.; Nitschke, J.; Berger, I.; Schimke, I.; Schierack, P. Fluorescence Dye Adsorption Assay to Quantify Carboxyl Groups on the Surface of Poly(Methyl Methacrylate) Microbeads. Anal. Chem. 2011, 83 (9), 3379-3385. https://doi.org/10.1021/ac103277s.

(6) Schiebel, J.; Böhm, A.; Nitschke, J.; Burdukiewicz, M.; Weinreich, J.; Ali, A.; Roggenbuck, D.; Rödiger, S.; Schierack, P. Genotypic and Phenotypic Characteristics in Association with Biofilm Formation in Different Pathotypes of Human Clinical Escherichia Coli Isolates. Applied and Environmental Microbiology 2017, AEM.0166017. https://doi.org/10.1128/AEM.01660-17.

(7) Frömmel, U.; Böhm, A.; Nitschke, J.; Weinreich, J.; Groß, J.; Rödiger, S.; Wex, T.; Ansorge, H.; Zinke, O.; Schröder, C.; et al. Adhesion Patterns of Commensal and Pathogenic Escherichia Coli from Humans and Wild Animals on Human and Porcine Epithelial Cell Lines. Gut Pathog 2013, 5 (1), 31. https://doi.org/10.1186/1757-4749-531.

(8) Rödiger, S.; Böhm, A.; Schimke, I. Surface Melting Curve Analysis with R. The $R$ Journal 2013, 5 (2), 37-53. 